\title{
Predictive value of aminotransferase and hepatitis B virus DNA levels on response to interferon therapy for chronic hepatitis B
}

\author{
A. S. F. Lok, ${ }^{1}$ M. G. Ghany, ${ }^{1}$ G. Watson ${ }^{2}$ and B. Ayola ${ }^{1}{ }^{1}$ Division of Gastroenterology, University of Michigan and VA \\ Medical Center, Ann Arbor, MI and ${ }^{2}$ Chiron Corp., Emeryville, CA, USA \\ Received 27 November 1997; accepted for publication 22 January 1998
}

SUMMARY. In a previously reported randomized controlled trial of interferon- $\alpha$ (IFN- $\alpha)$ for chronic hepatitis $\mathrm{B}$, we found a significant difference in response between Chinese adults with elevated vs normal pretreatment aminotransferase (ALT) levels. The aim of this study was to determine the correlation between serum hepatitis B virus (HBV) DNA levels and response to IFN therapy. HBV DNA levels in residual stored sera from patients who participated in the above trial were quantified by a branched DNA (bDNA) assay. Nominal logistic regression was used to estimate the probability of response to IFN treatment as a function of pretreatment ALT and/or HBV DNA levels. We found a significant $(P<0.01)$ correlation between the HBV DNA levels at midtreatment and response to IFN therapy. Response was achieved in 53\% of patients who had undetectable HBV DNA levels at midtreatment but in only $17 \%$ of those who remained HBV DNA positive $(P<0.01)$. In contrast, the probabilities of response for patients with baseline HBV DNA levels over the range 10 to 10000 million equivalents (MEq) $\mathrm{ml}^{-1}$ were almost identical. We also found a significant correlation between the pretreatment ALT levels and response to IFN therapy. The probabilities of response for patients with pretreatment ALT levels of 500 and $100 \mathrm{IU} \mathrm{l}^{-1}$ were higher than for patients with normal ALT levels by two and onefold, respectively. Our findings may help to improve the cost-effectiveness of IFN therapy for chronic hepatitis B by guiding the selection of patients for therapy and in optimizing the duration of treatment for the individual patient.

Keywords: aminotransferase level, chronic hepatitis B, hepatitis B virus DNA, interferon.

\section{INTRODUCTION}

Interferon- $\alpha$ (IFN- $\alpha)$ is at present the only approved treatment for chronic hepatitis B. Approximately $30-40 \%$ of white patients treated with a 3-6-month course of IFN- $\alpha$ at a dosage of 5 million units (MU) daily or $10 \mathrm{MU}$ thrice weekly have sustained suppression of hepatitis B virus (HBV) replication [1-6]. Several factors have been identified to be associated with a favourable response to IFN therapy, the most important being high serum aminotransferase (ALT)

\footnotetext{
Abbreviations: ALT, alanine aminotransferase; HBV, hepatitis B virus; IFN- $\alpha$, interferon- $\alpha$.

Correspondence: Dr Anna Lok, University of Michigan Medical Center, Division of Gastroenterology, 3912 Taubman Center, Box 0362, Ann Arbor, MI, USA.
}

and low HBV DNA levels [2,3,6-8]. However, most of the early studies used semiquantitative HBV DNA assays, which have wide interassay variability. In addition, multivariate analysis was rarely performed, so it is not clear if ALT or HBV DNA level is a more important independent predictive factor for response.

In the US multicenter trial of IFN- $\alpha 2 b$, with or without prednisone priming, Perrillo et al. found that baseline serum HBV DNA level was the most important independent predictive factor of response $(P=0.003)$ [6]. Approximately $50 \%$ of patients with baseline HBV DNA levels lower than $100 \mathrm{pg} \mathrm{ml}^{-1}$ responded to treatment with $5 \mathrm{MU}$ doses of IFN- $\alpha$ compared to $7 \%$ of patients with baseline HBV DNA levels that exceeded $200 \mathrm{pg} \mathrm{ml}^{-1}$. These results suggest that quantification of pretreatment serum HBV DNA level may help in the identification of patients 
who are likely to respond to therapy. However, more data are needed to determine if there is a discriminatory serum HBV DNA level above which response is unlikely to occur and treatment should therefore not be initiated.

Early studies reported that Oriental patients with chronic HBV infection respond less favourably to IFN- $\alpha$ therapy $[9,10]$. In a subsequent study that incorporated stratified randomization based on pretreatment ALT levels, Lok et al. found that Oriental patients with elevated pretreatment ALT levels had response rates similar to white patients, but the response was poor in patients with normal pretreatment ALT levels [11]. Although the basis for the difference in response was attributed to immune tolerance in the patients with normal pretreatment ALT levels, it was noted that these patients had higher pretreatment serum HBV DNA levels. Using a semiquantitative serum HBV DNA assay involving visual scoring of autoradiograms from directspot hybridization, $43(72 \%)$ of 60 patients with normal pretreatment ALT levels had serum HBV DNA scores of $3+$ or $4+$ compared to $17(31 \%)$ of 55 patients with elevated pretreatment ALT levels $(P<0.001)$. Thus, higher pretreatment serum HBV DNA levels may also contribute to the poor response to IFN- $\alpha$ therapy in Oriental patients with normal ALT levels.

IFN treatment in chronic hepatitis B is frequently accompanied by flares in ALT levels. These flares may be a reflection of IFN- $\alpha$-induced immune lysis of infected hepatocytes and have been interpreted to be an indicator of response. However, flares in ALT levels are not invariably associated with subsequent loss of hepatitis B e antigen (HBeAg), and response can occur in the absence of ALT flares. Thus, monitoring of ALT levels does not reliably predict response. Two recent studies found that monitoring of $\mathrm{HBeAg}$ and immunoglobulin M (IgM) hepatitis B core antibody (IgM HBcAb) levels using microparticle capture assay (IMx, Abbott Laboratories, N. Chicago, IL) during IFN- $\alpha$ treatment can predict subsequent response $[12,13]$. However, these assays are not readily available and the reliability of these markers as predictors for response need to be confirmed in larger scale studies. There are as yet no data on the role of serial quantification of serum HBV DNA levels during treatment as a predictor for subsequent loss of HBeAg.

In this study, we retested stored sera from a previously reported trial of IFN- $\alpha$ therapy in Chinese adults with chronic hepatitis B [11] using a sensitive, quantitative HBV DNA assay to: first, determine the predictive value of pretreatment serum HBV DNA level on subsequent response; second, evaluate if pretreatment serum HBV DNA level has any additive effect on ALT level in predicting response to IFN- $\alpha$ therapy; and third, determine the predictive value of serum HBV DNA levels at midtreatment and end-of-treatment on subsequent response to IFN- $\alpha$ therapy.

\section{MATERIALS AND METHODS}

\section{Sera and patient treatment groups}

Residual stored sera from patients who participated in a previously reported randomized controlled trial of IFN- $\alpha 2 b$, with or without prednisone priming, in Chinese adults with chronic hepatitis B [11] were reanalysed. In that trial, Chinese adults with chronic HBV infection who were HBeAg positive were randomized into three groups. Group A received oral prednisone at decreasing daily doses of $45 \mathrm{mg}, 30 \mathrm{mg}$ and $15 \mathrm{mg}$, each for 2 weeks, followed by a 2-week rest, and then 16 weeks of IFN- $\alpha 2 b$ (intron A) at doses of 10 MU subcutaneously thrice weekly. Group B received a 6-week tapering course of a matching oral placebo followed by a 2-week rest and then 16 weeks of IFN$\alpha 2 b$ at the same dose. Group $C$ received no treatment. Patients with normal pretreatment serum ALT levels (I) were randomized separately from those with elevated ALT levels (II) (mean of 3 monthly readings $>1.5$ times the upper limit of normal). Response was defined as sustained clearance of serum HBV DNA during and after therapy and clearance of HBeAg with or without clearance of hepatitis B surface antigen (HBsAg) within 12 months of the initiation of the study.

\section{Determination of HBV DNA level}

Sera collected at week 0 (baseline), week 6 (end of prednisone/placebo treatment), week 8 (onset of IFN- $\alpha$ therapy), week 16 (midway through the course of IFN- $\alpha$ therapy) and week 24 (end of IFN- $\alpha$ therapy) were tested for HBV DNA level using the branched DNA (bDNA) assay (Quantiplex ${ }^{\mathrm{TM}} \mathrm{HBV}$ DNA, Chiron Corporation, Emeryville, CA). Sera were available from more than $80 \%$ of the patients at most of the time points studied. In $35 \%$ of the patients, sera collected at week 12 were used as the 
midtreatment sample owing to unavailability of the week-16 samples.

The bDNA assay involves capture of HBV DNA to microwells via specific, synthetic oligonucleotide probes [14]. Target probes hybridize to the capture probes and 19 regions of the HBV genome. Detection of the captured hybrid complex is accomplished by the use of highly branched DNA amplifier molecules that hybridize to the target probes as well as probes linked to alkaline phosphatase. The resulting amplified signal is detected with dioxetane chemiluminescent substrate using a plate luminometer. The quantity of HBV DNA in each sample is read from a standard curve, which is generated by plotting the luminescence of four known standards of HBV DNA that are included in each assay. The detection limit of this assay is 0.7 million equivalents (MEq) of HBV genome $\mathrm{ml}^{-1}$.

\section{Statistical analysis}

Statistical analyses were performed on the natural logarithm $\log _{\mathrm{e}}$ ALT and $\log _{\mathrm{e}}$ serum HBV DNA values to satisfy statistical model assumptions. When necessary, these values were transformed back to the original scale for presentation. The two treatment groups were combined for analysis of response to IFN- $\alpha$ therapy because there was no significant difference in response rates between the groups with (A) and without (B) prednisone priming $(P>0.1)$. Multivariate analysis of variance (MANOVA) for repeated measurement data was used to compare pretreatment ALT and serial serum HBV DNA levels between treatments and across treatment time points. Nominal logistic regression [15] was used to estimate the probability of response to IFN- $\alpha$ treatment as a function of pretreatment ALT and/or HBV DNA levels. Stepwise regression was used to determine whether baseline serum HBV DNA levels have any additive effect on pretreatment ALT levels in predicting response to therapy.

\section{RESULTS}

Changes in serum HBV DNA levels in treated patients and controls

A significant decrease in serum HBV DNA levels was observed midway through the course of IFN- $\alpha$ therapy in the treated patients (Fig. 1). Prednisone priming resulted in a significant $(P<0.01)$ increase in $\log _{\mathrm{e}}$

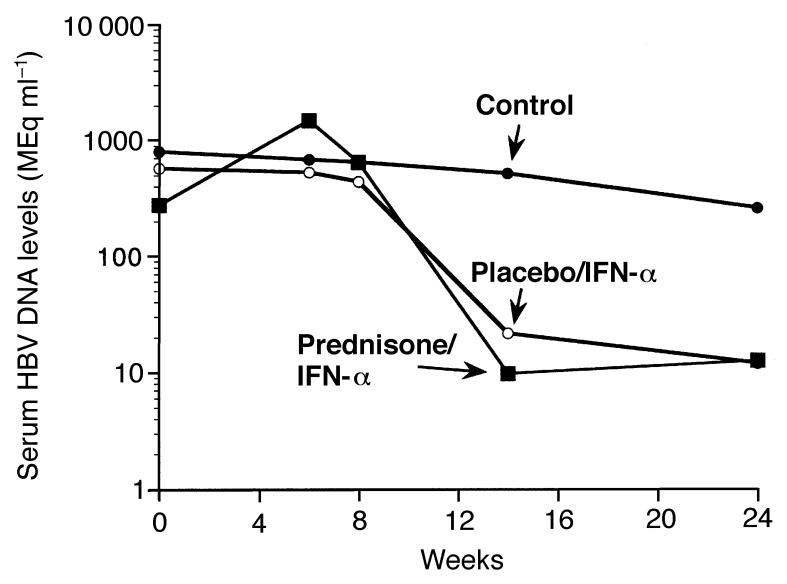

Fig. 1 Serial serum HBV DNA levels in the IFN- $\alpha$-treated patients and controls showing a significant decrease in serum HBV DNA levels in the two treated groups by weeks $12-16$ (mid-way through the course of IFN- $\alpha$ therapy) and a significant increase in serum HBV DNA levels at week 6 in the prednisone-primed group.

serum HBV DNA levels, but response was not affected by the extent of prednisone-induced increase in serum HBV DNA levels. The mean percentage change in serum HBV DNA levels between week 0 and week 6 was $+38 \%$ for the prednisone-primed and $-3 \%$ for the placebo-primed patients. Among the prednisoneprimed patients, serum HBV DNA levels at week 8 were still significantly increased compared with the baseline values. At week 24, serum HBV DNA levels were significantly lower than the baseline values in the treated patients but not in the controls.

\section{Correlation between response and pretreatment serum HBV DNA levels}

The baseline serum HBV DNA levels were similar in the three treatment groups (Table 1). Although the responders tended to have lower mean $\log _{\mathrm{e}}$ baseline serum HBV DNA levels compared with the nonresponders: $\quad 5.92 \pm 2.16$ vs $6.05 \pm 2.20 \mathrm{Meq} \mathrm{ml}^{-1}$ $(P=0.05)$, there was no significant correlation between baseline serum HBV DNA levels and response to IFN- $\alpha$ therapy (Fig. 2). The probabilities of response (95\% CI) for baseline serum HBV DNA levels of 10 , 100,1000 , and $10000 \mathrm{MEq} \mathrm{ml}^{-1}$ were $26 \%$ (11-52\%), 25\% (15-40\%), 24\% (15-37\%) and 23\% (10-45\%), respectively. 


\begin{tabular}{|c|c|c|c|}
\hline & $\begin{array}{l}\text { Prednisone } \\
+ \text { IFN- } \alpha\end{array}$ & $\begin{array}{l}\text { Placebo } \\
+ \text { IFN- } \alpha\end{array}$ & Control \\
\hline \multicolumn{4}{|l|}{ Elevated ALT } \\
\hline No. of patients & 20 & 18 & 15 \\
\hline ALT level (IU l $\left.{ }^{-1}\right)^{*}$ & $157(62-530)$ & $128(61-770)$ & $109(85-421)$ \\
\hline $\begin{array}{l}\log _{\mathrm{e}} \mathrm{HBV} \text { DNA level } \\
\left(\mathrm{MEq} \mathrm{ml}^{-1}\right) \text { geometric } \\
\text { mean } \pm \mathrm{SD}\end{array}$ & $4.9 \pm 2.6$ & $6.2 \pm 1.5$ & $6.2 \pm 2.2$ \\
\hline \multicolumn{4}{|l|}{ Normal ALT } \\
\hline No. of patients & 14 & 17 & 16 \\
\hline ALT level (IU l l'-1)* & $28(7-55)$ & $24(10-55)$ & $20(12-54)$ \\
\hline $\begin{array}{l}\log _{\mathrm{e}} \mathrm{HBV} \text { DNA level } \\
\left(\mathrm{MEq} \mathrm{ml}^{-1}\right) \text { geometric } \\
\text { mean } \pm \mathrm{SD}\end{array}$ & $6.6 \pm 1.2$ & $6.6 \pm 2.7$ & $7.2 \pm 1.8$ \\
\hline
\end{tabular}

Table 1 Baseline (week 0) serum alanine aminotransferase (ALT) and HBV DNA levels in the three treatment arms

*Mean (range).

\section{Correlation between response and midtreatment serum} HBV DNA levels

There was a significant $(P<0.01)$ correlation between response and serum HBV DNA levels at midtreatment. Response was achieved in 53\% of patients whose serum HBV DNA levels had become undetectable in the bDNA assay $\left(<0.7 \mathrm{MEq} \mathrm{ml}^{-1}\right)$ by weeks 12-16 (4-8 weeks after the onset of IFN- $\alpha$ therapy), but in only $17 \%$ of those who remained serum HBV DNA positive $(P<0.01)$. The probabilities of response $(95 \% \mathrm{CI})$ for patients with serum HBV DNA levels of <0.7, 10, 100 and $1000 \mathrm{MEq}$ $\mathrm{ml}^{-1}$ midway through treatment were $50 \%$

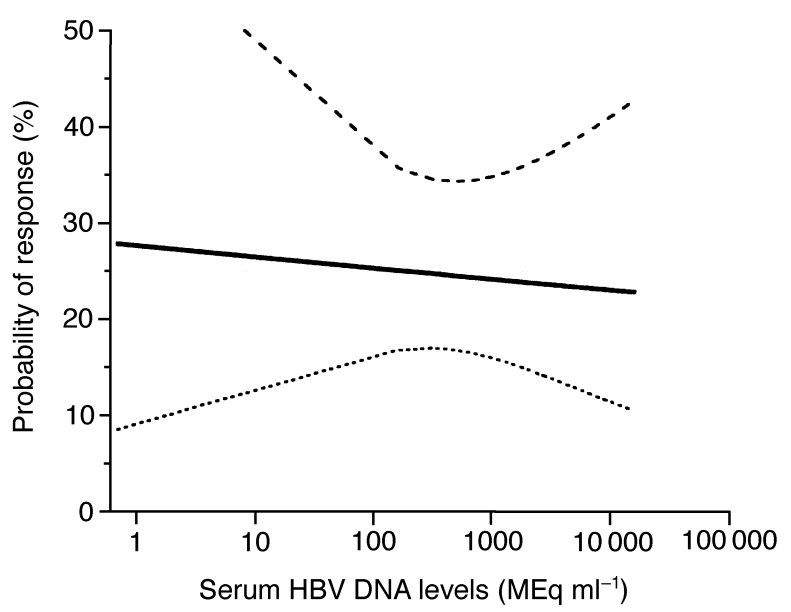

Fig. 2 Probability of response $(95 \% \mathrm{CI})$ in relation to baseline (week 0) serum HBV DNA levels in the IFN- $\alpha$-treated patients.
(30-70\%), 21\% (10-36\%), 8\% (2-23\%) and 3\% (0.3-16\%), respectively (Fig. 3).

Correlation between response and serum HBV DNA levels at the end of treatment

There was a significant correlation between response and serum HBV DNA levels at the end of treatment. At the end of treatment, $90 \%$ of the responders had undetectable serum HBV DNA levels. Of the patients who were still serum HBV DNA positive by the bDNA assay midway through the course of IFN- $\alpha$ therapy, $18 \%$ had a $>50 \%$ decrease in serum HBV DNA levels and $11 \%$ became serum HBV DNA negative at the end of treatment. The probabilities of response $(95 \% \mathrm{CI})$ for patients with serum HBV DNA levels of $<0.7,10,100$ and $1000 \mathrm{MEq} \mathrm{ml}^{-1}$ at the end of treatment were $49 \%$ (4-96\%), 11\% (0.4-82\%), 2\% (0-68\%) and $0.4 \%$ (0-58\%), respectively (Fig. 4).

Correlation between response and pretreatment serum ALT levels

There was a significant $(P<0.01)$ correlation between the pretreatment ALT levels and response to IFN- $\alpha$ therapy. The probabilities of response $(95 \% \mathrm{CI})$ for pretreatment ALT values of 40, 100, 200 and $500 \mathrm{IU} \mathrm{l}^{-1}$ were $16 \%(8-30 \%), 26 \%(17-39 \%), 37 \%(22-53 \%)$ and $52 \%(27-77 \%)$, respectively (Fig. 5). Among the controls, there was also a progressive, but insignificant $(P>0.5)$, increase in the rate of spontaneous HBeAg clearance with the baseline ALT levels. Irrespective of 


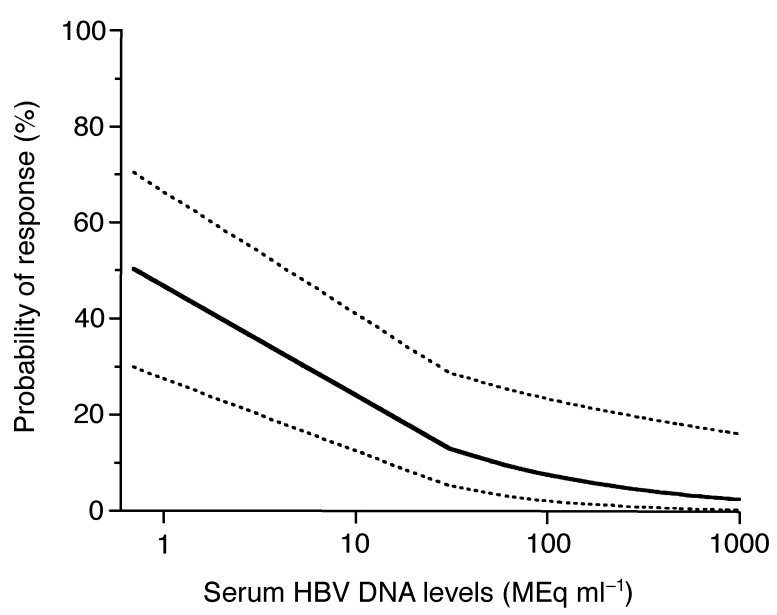

Fig. 3 Probability of response $(95 \% \mathrm{CI})$ in relation to midtreatment (weeks 12-16) serum HBV DNA levels in the IFN- $\alpha$-treated patients.

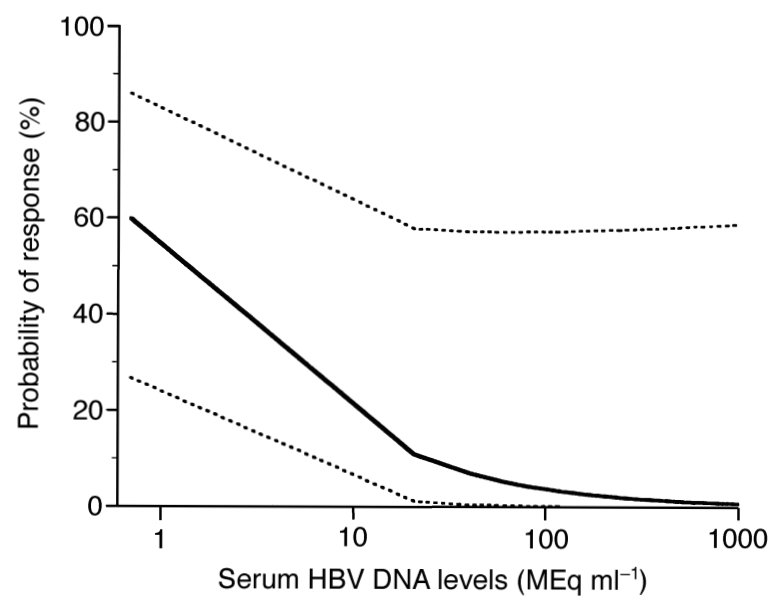

Fig. 4 Probability of response (95\% CI) in relation to serum HBV DNA levels at the end of treatment (week 24) in the IFN- $\alpha$-treated patients.

the pretreatment ALT levels, the rate of HBeAg clearance was higher in the treated patients compared with the controls (Fig. 5). The difference in the rate of $\mathrm{HBeAg}$ clearance increases as ALT level increases. However, this difference was not statistically significant $(P=0.15)$ over the entire range of ALT levels studied.

\section{Predictive value of pretreatment HBV DNA and ALT levels combined}

While pretreatment serum HBV DNA level on its own correlated poorly with response to IFN- $\alpha$ therapy, the combination of baseline serum HBV DNA and ALT levels resulted in a significantly $(P=0.05)$ stronger predictor of response than pretreatment ALT level alone. Interestingly, the highest response rate was observed in patients with both high pretreatment ALT and high serum HBV DNA levels (Fig. 6). Among the patients with elevated pretreatment ALT levels, response was better in those with high baseline serum HBV DNA levels. In contrast, patients with normal pretreatment ALT levels had a uniformly poor response, irrespective of their baseline serum HBV DNA levels.

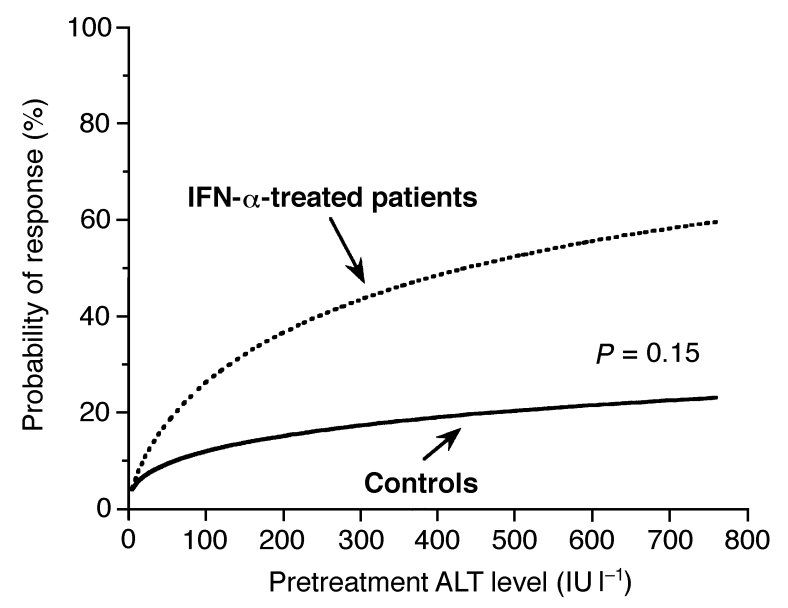

Fig. 5 Probability of response/spontaneous clearance of $\mathrm{HBeAg}$ in relation to baseline (week 0) ALT levels for IFN- $\alpha$ treated patients and controls.

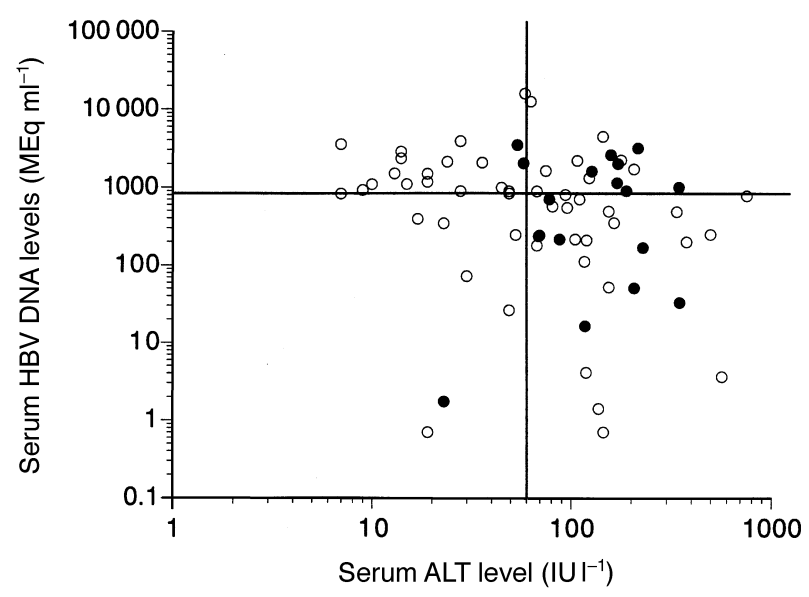

Fig. 6 Relationship between baseline (week 0) serum HBV DNA and ALT levels and response to IFN- $\alpha$ therapy. Patients were divided into four groups based on pretreatment ALT ( $<$ or $\geq 60 \mathrm{IU} \mathrm{l}^{-1}$ [1.5 times the upper limit of normal]), and HBV DNA (< or $\geq$ median) levels. Solid circles, responders; open circles, non-responders. 


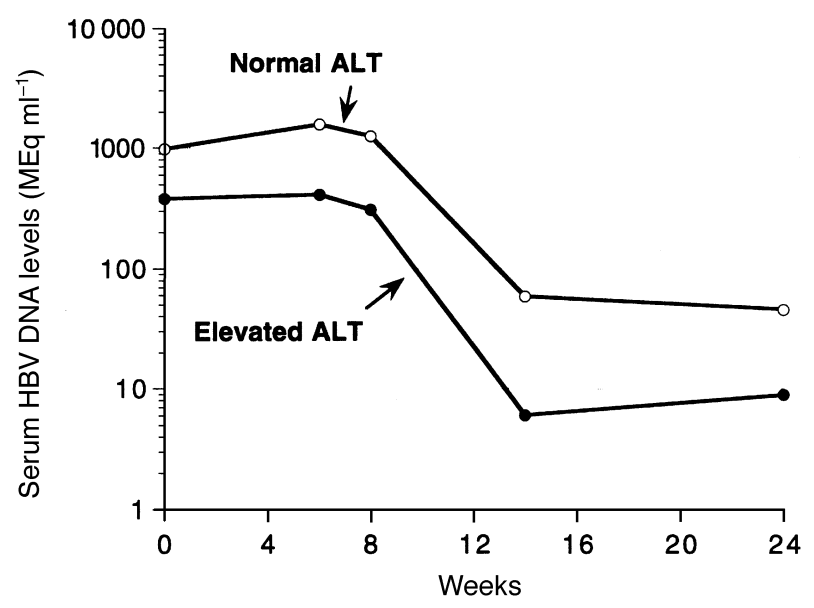

Fig. 7 Serial serum HBV DNA levels in the IFN- $\alpha$-treated patients who had elevated vs normal pretreatment ALT levels.

Patients with normal pretreatment ALT levels also maintained higher serum HBV DNA levels compared to those with elevated pretreatment ALT levels throughout the study period, even though the rates of decrease in $\log _{\mathrm{e}}$ serum HBV DNA levels during treatment were similar (Fig. 7).

\section{DISCUSSION}

Using a sensitive and highly reproducible quantitative HBV DNA assay, we found that serum HBV DNA levels midway through the course of therapy correlated significantly $(P<0.01)$ with subsequent response to IFN- $\alpha$ treatment in Chinese adults with chronic HBV infection. Response was achieved in $53 \%$ of patients who had undetectable HBV DNA levels $(<0.7 \mathrm{MEq}$ $\mathrm{ml}^{-1}$ ) at midtreatment, but in only $17 \%$ of those who remained HBV DNA positive. Owing to the unavailability of serum samples at week 16 (8 weeks after the onset of IFN- $\alpha$ therapy), the midtreatment data in 35\% of patients were based on samples collected at week 12 ( 4 weeks after the onset of IFN- $\alpha$ therapy). Thus, it is possible that reliable prediction of response to IFN- $\alpha$ treatment can be made by monitoring serum HBV DNA levels earlier during the course of therapy (after 2-4 weeks). Unfortunately, we do not have sufficient stored sera from the early phase of treatment to test our hypothesis. It is important to note that our findings are based on retrospective analyses and that some patients may be slow, rather than non-responders. Further prospective studies are needed to determine if the opti- mal duration of IFN- $\alpha$ treatment for chronic hepatitis B can be tailored according to the individual's rate of decrease in serum HBV DNA levels during the first 1-2 months of therapy so that treatment can be withdrawn from those who are unlikely to respond and prolonged for slow responders.

In contrast to the predictive value of midtreatment HBV DNA levels, we found no correlation between baseline serum HBV DNA levels and response to IFN- $\alpha$ therapy. The probabilities of response for patients with baseline serum HBV DNA levels over the range of 10 to $10000 \mathrm{MEq} \mathrm{ml}^{-1}$ were almost identical. Substituting the week 0 (baseline) with week 8 (pre-IFN- $\alpha$ ) serum HBV DNA values had no significant effect on the probability plots. Despite a significant increase in serum HBV DNA levels in the prednisone-primed group, there was no correlation between response and the extent of increase in serum HBV DNA levels induced by prednisone priming.

Our findings differ from that of Perrillo et al. [6] who reported that pretreatment serum HBV DNA level was the most important independent predictive factor of response. This discrepancy may be related to ethnic differences in the patient population, the use of different HBV DNA quantification assays, or the inclusion of patients with normal pretreatment ALT levels in our study. It is unlikely that the choice of HBV DNA quantification assay accounts for the different results between the two studies as the Chiron bDNA assay has been shown to correlate well with the Abbott liquid hybridization assay [16]. Although the patients with normal pretreatment serum ALT levels had higher mean $\log _{\mathrm{e}}$ baseline serum HBV DNA levels than those with elevated ALT levels, this difference was not significant and is unlikely to account for the lack of correlation between response and baseline serum HBV DNA levels. Whether the differences between our findings and those of Perrillo et al. can be attributed to differences in ethnic origin, age at infection or predominant HBV genotype is not clear. Several investigators also found that pretreatment aspartate aminotransferase (AST) or ALT, but not serum HBV DNA level, were predictors of response to IFN- $\alpha$ therapy [2-4]. Thus, the predictive value of pretreatment serum HBV DNA level on response to IFN- $\alpha$ therapy for chronic hepatitis B remains to be confirmed.

In accordance with other investigators [2,3,5], we found that pretreatment serum ALT level was a signifi- 
cant predictor of response to IFN- $\alpha$ therapy in Chinese adults with chronic HBV infection. The probabilities of response for patients with pretreatment ALT levels of $500 \mathrm{IU} \mathrm{l}^{-1}$ and $100 \mathrm{IU} \mathrm{l}^{-1}$ were higher than for patients with normal ALT levels by two and onefold, respectively. The rate of spontaneous HBeAg clearance also increased with the baseline ALT levels, but the treated patients maintained higher rates of HBeAg clearance than controls over the entire range of ALT levels studied. These data suggest that even patients with very high (>10-fold the upper limit of normal) ALT levels may derive benefit from IFN- $\alpha$ therapy.

Our analysis showed that pretreatment HBV DNA level, in combination with pretreatment ALT level, provided better predictive value than either parameter alone. The current recommendation for treatment of chronic hepatitis B involves a 4-6-month course of IFN- $\alpha$ in doses of $5 \mathrm{MU}$ daily or $10 \mathrm{MU}$ thrice weekly. This treatment is expensive and associated with frequent side-effects. Even among patients with very high pretreatment ALT levels $\left(500 \mathrm{IU} \mathrm{l}^{-1}\right)$, the probability $(95 \% \mathrm{CI})$ of response was only $52 \%(27-77 \%)$. Additional parameters, such as HBV DNA levels, which can differentiate responders from non-responders prior to or during the course of treatment, may improve the cost-effectiveness of therapy and avoid unnecessary adverse effects.

In summary, we found that midtreatment but not pretreatment serum HBV DNA levels correlated with response to IFN- $\alpha$ therapy in Chinese adults with chronic HBV infection. Consistent with earlier studies, we found that pretreatment serum ALT levels correlated significantly with response. A significantly stronger correlation with response was observed when pretreatment serum HBV DNA and ALT levels were combined than when pretreatment ALT levels were considered alone. Surprisingly, among the patients with elevated ALT levels, the responders tended to have higher baseline serum HBV DNA levels. The rationale for this paradox is not clear. However, an increase in serum HBV DNA levels is sometimes observed prior to ALT flares that precede spontaneous HBeAg seroconversion. Our findings may help to improve the cost-effectiveness of IFN- $\alpha$ therapy for chronic hepatitis B by guiding the selection of patients for therapy and in optimizing the duration of treatment for the individual patient. We acknowledge that these findings were based on Chinese adults and may not apply to other patient populations and that our results need to be confirmed in prospective studies before clinical guidelines can be established. It is also possible that our observations may not apply to treatment with new antiviral agents. Clinical trials of these new treatment modalities should incorporate prospective assessment of factors that can predict response prior to and during therapy.

\section{ACKNOWLEDGEMENTS}

The bDNA assay kits were provided by Chiron Corporation.

\section{REFERENCES}

1 Alexander GJM, Brahm J, Fagan EA et al. Loss of HBsAg with interferon therapy in chronic hepatitis B virus infection. Lancet 1987; 2: 66-69.

2 Scully LJ, Shein R, Karayiannis P, McDonald JA, Thomas HC. Lymphoblastoid interferon of chronic HBV infection. A comparison of 12 Vs 24 weeks of thrice weekly treatment. J Hepatol 1987; 5: 51-58.

3 Hoofnagle JH, Peters M, Mullen KD et al. Randomized, controlled trial of recombinant human $\alpha$-interferon in patients with chronic hepatitis B. Gastroenterology 1988; 95: 1318-1325.

4 Saracco G, Mazzella G, Rosina F et al. A controlled trial of human lymphoblastoid interferon in chronic hepatitis B in Italy. Hepatology 1989; 10: 336-341.

5 Brook MG, Chan G, Yap I et al. Randomized controlled trial of lymphoblastoid interferon alfa in Europid men with chronic hepatitis B virus infection. Br Med J 1989; 299: 652-659.

6 Perrillo RP, Schiff ER, Davis GL et al. Hepatitis Interventional Therapy Group. A randomized, controlled trial of interferon alfa- $2 b$ alone and after prednisone withdrawal for the treatment of chronic hepatitis B. N Engl J Med 1990; 323: 295-301.

7 Perrillo RP. Treatment of chronic hepatitis B with interferon: experience in western countries. Semin Liver Dis 1989; 9: 240-248.

8 Brook MG, Karayiannis P, Thomas HC. Which patients with chronic hepatitis B virus infection will respond to $\alpha$-interferon therapy? A statistical analysis of predictive factors. Hepatology 1989; 10: 761-763.

9 Lok ASF, Lai CL, Wu PC, Leung EKY. Long-term follow-up in a randomized controlled trial of recombinant alphainterferon in Chinese patients with chronic hepatitis B infection. Lancet 1988; 2: 298-302.

10 Lai CL, Lok ASF, Lin HS, Wu PC, Yeoh EK, Yeung CY. Placebo controlled trial of recombinant alpha-interferon in Chinese HBsAg-carrier children. Lancet 1987; 2: 877-880. 


\section{A. S. F. Lok et al.}

11 Lok ASF, Wu PC, Lai CL et al. A controlled trial of interferon with or without prednisone priming for chronic hepatitis B. Gastroenterology 1992; 102: 2091-2097.

12 Perrillo R, Mimms L, Schechtman K, Robbins D, Campbell C. Monitoring of antiviral therapy with quantitative evaluation of HBeAg: a comparison with HBV DNA testing. Hepatology 1994; 18: 1306-1312.

13 Marinos G, Smith H, Naoumov NV, Williams R. Quantitative assessment of serum IgM anti-HBc in the natural course and during interferon treatment of chronic hepa- titis B virus infection. Hepatology 1994; 19: 303-311.

14 Hendricks DA, Stowe BJ, Hoo BS et al. Quantitation of HBV DNA in human serum using a branched DNA (bDNA) signal amplification assay. Am J Clin Pathol 1995; 104: 537-540.

15 Hosmer DW, Lemeshow S. Applied Logistic Regression. New York: John Wiley; 1989.

16 Kapke GF, Sheffler S, Hunt D, Frederick C. Comparison of the chiron quantiplex ${ }^{\mathrm{TM}}$ hepatitis B DNA assay and the Abbott hepatitis B DNA assay. Clin Chem 1994; 40: 1045. 